\title{
A Survey on Understanding the Perception and Awareness Towards a Circular Economy: A Comparative Study Between Nepal and the USA
}

Sugam Upadhayay, Student

s.upadhayay.177@westcliff.edu

Omaima Alqassimi, Student

o.alqassimi.110@westcliff.edu

\begin{abstract}
This article offers a comparative analysis of the perception and awareness people have concerning the circular economy (CE) in Nepal and the United States of America (USA). The survey in the form of online questionnaires were distributed through convenience sampling and data was collected from 29 respondents in Nepal and 25 in the USA. The results indicate that, across the sampled countries, though respondents were highly concerned about the environment and resources utilization, their perception and understanding of CE principals and its applicability were limited to the concept of reuse, recycle and remanufacture (3R). Similarly, organizational involvement in CE activities were found to be significantly low in both countries, indicating no structural or operational level support such as creating job positions for CE officers. Additionally, the practice of publishing sustainability and circularity reports to enable the CE were not found during the data analysis procedure. In comparison to Nepal, USA respondents picked inter and intra organizational collaboration and cooperation along with research and development (R\&D) as an important enabler of CE. Finally, policy level interventions through mandatory and voluntary regulations, subsidization of CE activities and involvement of governmental and non-governmental agencies were recommended in creating a positive perception and awareness of CE.
\end{abstract}

Keywords: Circular economy, comparative study, awareness, perception 


\section{Research Background}

A circular economy (CE) emphasizes relooping resources back into the production and consumption cycle, aiming to prolong the life of the resources and simultaneously increase their value. This type of economy is a shift from the linear model of consumption which focuses on the take, make and dispose model to instead focus on the take, make and reutilize strategy (Upadhayay \& Alqassimi, 2018). The application of circularity not only offers environmental advantages but also manifests multiple financial and non-financial benefits for companies, making them competitive. In the European Union (EU), transitioning to $C E$ and shifting to an alternative production material would formulate savings of US \$340-380 billion and could eradicate 1.3 million tons of carbon dioxide annually (Ellen MacArthur Foundation, 2013).

The CE is based on the principle of resource preservation through restorative and regenerative approaches; the most widely used ethos is the $3 R$ approach of reuse, recycle and remanufacture. However, CE goes beyond waste management; it focuses on the efficient management of resources from the beginning of the design phase. CE balances the flow and exchange of resources between the environment and industries (Liu, Li, Zuo, Zhang, \& Wang, 2009).

Skawinska and Zalewski (2018) show how CE has brought a new paradigm for sustainability. A well-managed reverse logistics, sufficiently developed performance and well-established sharing economy enables the CE. That is the reason the transition from a linear to a circular economy alone presents the opportunity to save $\$ 4.5$ trillion globally by 2030 (Houten \& Ishii, 2019). The practice of CE fundamentals in the global e-waste market, which is worth $\$ 62.5$ billion, will decrease the price of e-products by $7 \%$ by 2030 and by $14 \%$ by 2040 (World Economic Forum, 2019). Ellen MacArthur Foundation (2013), a UK registered charity which focuses on $\mathrm{CE}$, states if $\mathrm{CE}$ concepts were implemented, the cost of remanufacturing mobile phones could be reduced by $50 \%$.
Moreover, when it comes to the formulation and implementation of CE principles, companies are still lacking a strategic move. Liu and Bai (2014) explain that there is still an existent gap between the awareness of and the actual implementation of CE. Whereas, Liu, Li, Zuo, Zhang, and Wang (2008) inferred that the scarcity and high cost of resources along with supportive government philosophies are factors that fostered the implementation of CE in China.

Furthermore, the European Union (EU) is an initiator in terms of implementing CE through numerous legislations: EU countries like Denmark, the Netherlands, Scotland and Sweden have legally formulated the necessary polices to foster the concepts of reuse and recycling of resources for conservation. And lately, the United States of America is also inclined to incorporate the CE principles. As per research carried by ING, a Dutch multinational banking and financial services corporation, in 2019 , twice the number of the US companies in comparison to 2018 says their strategic decision is focused on sustainability through the principles of CE (Peters, 2019). These US companies are focusing more on the sustainable use of resources through an effective reuse and recycle approach. However, this scenario in the least developed countries, like Nepal, is far from the reality.

It is undeniable that the trend of producing and consuming products and services is changing, and countries are becoming more responsible towards the ethical extraction and use of resources. Though the USA was not a trend setter in CE implementation (Davis \& Hall, 2006), nowadays, the country has started to practice CE. The Ellen McArthur Foundation plays a pivotal role in bringing globally disbursed C-Suits and companies to manage and broaden their strategy from waste to resource management. In addition, companies like Patagonia, Google and Renault are reworking and redesigning themselves in order to use the close loop strategy, a strategy which aims to reuse resources and keep them in the production and consumption cycle rather than 
dumping them in landfills. In the context of Nepal, such initiation from regulatory or entrepreneurial dimensions are still minuscule.

To sum up, consumers and producers who are aware of the importance of CE, irrespective of their geographic variations, support CE activities which emphasize ethical and responsible uses of resources which have ramifications in terms of positive economic, social and environmental outcomes. The successful implementation of CE can occur when stakeholders are aware of its concepts and applicability while laws and regulations also support and benefit the transition.

\section{Previous Studies and Need for Further Studies}

The perception and awareness of CE plays an important role in the adoption of $\mathrm{CE}$ philosophies. Though the significance of CE is something that is noted and understood in developing countries, there is only a limited amount of research regarding the perception in the least developed ones. A plethora of research has been done focusing on environmental awareness, its conservation and resource utilization with the $3 \mathrm{R}$ approach, and yet, there is only limited research regarding people's perception and awareness of CE which is exponentially important to formulate and implement CE policies. Adams, Osmani, Thorpe, and Thornback (2017) explain that there has been no signifcant reaserch executed on the CE from a system level persective. Similarly, out of the three major domains of CE (economic benefit, environmental impact and resource scarcity), the environmental domain is much more developed than the remaning two (Liakos et al., 2019).

The online survey used in this study provides information regarding the level of awareness and perception of people towards CE in the context of Nepal and United States of America (USA). This comparative research between the two economies, which is distinct in terms of technological, socio-cultural, economic, political and legal aspects, aims to aid regulators and environmentalists in the development of policy level interventions, guidance for students to further introspection in the field, and support for businesspeople to remodel their resource utilization cycles with the CE modality.

\section{Research Design and Data Collection}

For this comparative analysis, Nepal and the United States of America (USA) were chosen. The USA is the most economically competitive country among the developed nations with its gross domestic product being worth \$20.5 trillion in 2018 (World Bank, 2019). The country is technologically advanced and has invested tremendously in research and development.

In opposition, as per the World Bank, Nepal falls into the category of the least developed nation in the world with its gross domestic product being worth $\$ 28.81$ billion in 2018 (World Bank, 2019). This fact, further coupled with the poverty, high illiteracy rates and lagging and redundant technologies, has reduced Nepal's capacity to bring structural change in order to adopt CE. However, the fiscal policy of Nepal in 2019 has envisioned and desires to create new smart cities which aim to use information communication technologies (ICT) and the creation of eco-friendly cities (Ministry of Finance, 2019). Slowly, companies in Nepal are becoming more aware of how to reduce their carbon footprint which is also one of the domains of $\mathrm{CE}$.

\section{Questionnaire Design}

The data collection instrument used for the primary analysis was a questionnaire with preselected answers. The question types ranged from single choice to multiple choice questions as well as the integration of Likert scales. The questionnaire was divided into multiple sections, each with sub-questions. Meanwhile, the demographic section collected respondents' information including gender, age, education level, nature of organization and the location of their companies. The subject matter section included the assessment of the respondent's familiarity with the CE terminology and their best description of the approach and methodology of what CE includes; further, respondents' consciousness and thoughts towards the limitation of resources and their protection were questioned as well as their perception towards CE which included subquestions on the importance of $C E$ to their 
organizations. Similarly, questions relating to organization involvement and approach undertaken by their organizations were asked, as well as the respondent's readiness to participate in ridesharing and renting models were questioned. The final question gathered information regarding the right time to implement CE philosophies in their organization. In total, there were nine sections with subquestions included in each.

\section{Questionnaire Distribution and Results}

The questionnaire distribution and response collection were done through the use of Google Forms. The responses were automatically stored in Google Drive and did not require any researcher intervention to store the responses. The link to the survey questions was sent to each respondent's email address. Respondents with work experiences from Nepal and the USA were selected. Convenience sampling was incorporated for selecting the respondents. But equal caution was maintained to not have responses from the same company as it would not make the sample representative. In order to ensure a representative sample within the population chosen, the questionnaires were distributed to the diverse nature of companies, like banking, manufacturing, aviation, academic institutions et cetera. The responses were collected between February $15^{\text {th }}$ to July $11^{\text {th }}$, 2019. The use of the online platform eased the data collection process. A small portion of the respondents were neither from the USA nor Nepal, and as these responses were not within the scope of the study, they were excluded.

\section{Research Findings}

This segment offers the findings from the descriptive and inferential analysis. It includes sections regarding the demographic's details, the level of perception and awareness of the respondents towards $\mathrm{CE}$, their views on $\mathrm{CE}$ approaches and their level of awareness on the urgency to imply CE activities in their organizations.

\section{Demographics of the Respondents}

For the survey, the respondents that had current or previous work experiences were chosen to get an idea regarding the organizational level involvement in $\mathrm{CE}$ approaches. A total of 54 responses were collected, 29 from Nepal and 25 from the USA.

\begin{tabular}{lll}
\hline & Number & $\%$ \\
\hline Gender & 35 & \\
$\quad$ Male & 19 & 64.8 \\
$\quad$ Female & 1 & 35.2 \\
Education & 10 & 1.9 \\
$\quad$ High School & 40 & 18.5 \\
$\quad$ Bachelor & 3 & 74.1 \\
$\quad$ Master & & 5.6 \\
$\quad$ Doctorate/PhD & 29 & \\
Country & 25 & 53.7 \\
$\quad$ Nepal & & 46.3 \\
$\quad$ United States & 7 & \\
Management & 40 & 13 \\
$\quad$ Entry Level & 74.1 \\
$\quad$ Mid- Level & 7 & 13 \\
$\quad$ Top Level & 44 & 81.5 \\
Nature of Organization & 10 & 18.5 \\
Service Delivery & 54 & 100 \\
$\quad$ Manufacturing & & \\
Total &
\end{tabular}

Table 1. The demographics of the samples

Out of the sample, the majority of the respondents were male, had a master's degree, and held mid-level job positions within the service industry (see Table 1).

\section{Knowledge about the Circular Economy}

As shown in Table 2, a moderate proportion of the respondents from both countries had basic knowledge of CE terminology but were unclear about its exact purpose. Specifically, $27.6 \%$ in Nepal and $40 \%$ in the USA were entirely unaware of the concept (see Table 2). Similarly, in each sampled country, a majority of respondents, $67.9 \%$ in Nepal and $56 \%$ in the USA, specified that they believed the CE was related to the $3 R$ approach which, in reality, is only a small scope of CE. This fact aligns with the findings of Kannan and Hasanagic (2018), which determined that a majority of people are not aware of the CE concepts. 


\begin{tabular}{|c|c|c|c|c|}
\hline & $\begin{array}{l}\text { I could easy define } \\
\text { it with its } \\
\text { application. (\%) }\end{array}$ & $\begin{array}{l}\text { I have heard the term } \\
\text { before, but I am not } \\
\text { sure. }(\%)\end{array}$ & $\begin{array}{l}\text { I am totally } \\
\text { unaware about } \\
\text { it. }(\%)\end{array}$ & Total \\
\hline Nepal & 10.3 & 62.1 & 27.6 & $100 \%(29)$ \\
\hline U.S. & 0.0 & 60.0 & 40.0 & $100 \%(25)$ \\
\hline
\end{tabular}

Table 2. Familiarity with the CE terminology

In regards to methodologies that describe $\mathrm{CE}$, though most respondents marked that it was similar to the $3 R$ approach, Americans outnumbered Nepalese respondents in thinking of $\mathrm{CE}$ as a type of resource management; Americans were relativity high in claiming terminology such as sharing economy (32\%), symbiosis (32\%) and performance economy (16\%) which are aligned to the CE domain. This type of finding was low in the context of Nepal where familiarity with the terminology equated to sharing economy (10.3\%), symbiosis $(6.9 \%)$ and performance economy $(0.0 \%)$

\section{Organization Involvement Status}

One of the major objectives of this research was to determine the respondents' perceptions of their organizational involvement in CE related activities. In this matter, only $48 \%$ of Americans and $34.5 \%$ of Nepalese believed their companies were involved in CE activities; whereas, $24.1 \%$ of Nepalese and $20 \%$ of Americans said they had no idea. Most of the respondents thought their organizations were involved in CE due to $3 R$ activities. Only $4 \%$ of respondents from the USA said their organizations implemented CE concepts from the beginning phase of designing their products and services. This finding demonstrates that CE implementation is more focused on waste management than resource management in both of the sampled countries.

Due to the fact that the data collected was inclined towards the service industry, there were no take-back-programs that were applicable to the manufacturing sectors. A higher percent of interdepartmental collaboration was reported in the USA (33.3\%) which was $24.1 \%$ in Nepal. Further, $16.7 \%$ of respondents in the USA and $6.9 \%$ in Nepal said their organizations had collaboration between the firms. Furthermore, the internal and external collaboration between departments and firms, which was more notably practiced in American companies, favors symbiosis. Symbiosis is a state of collaboration and cooperation among the departments where the output from one department, if it is not the final product, is made into an input for another department or firm. The aim of this state is to extend the value of the output rather than dumping it in a landfill or incinerating it (Upadhayay \& Alqassimi, 2018). Symbiosis explicitly focuses on the close loop strategy and focuses on increasing the life of products.

\section{Perception Towards CE}

As presented in Table 3 below, questions were integrated using a five-point Likert scale, where 1 represented very important and 5 represented not important at all. A statement asking respondents about their perception of the importance of CE for their organization found that $51.7 \%$ in Nepal and $41.7 \%$ in the USA agreed and strongly agreed of its importance. Whereas $34.5 \%$ and $37.5 \%$ respectively maintained their neutrality to the statement, and $13.8 \%$ in Nepal and $20.8 \%$ in the USA identified that CE is not important, or not important at all to their organizations.

Subsequently, Table 3 also depicts the average score of employee perception towards the importance of CE for their organizations. The average was 2.45 and 2.63 in Nepal and the USA respectively which lies between neutral (3) and important (2) on the Likert scale. Importantly, an inferential analysis was used for the same Likert Scale statement. An independent sample T test was conducted to compare the perception of CE in Nepal and America. The test concluded that there was no significant difference in perception as the scores for Nepal's ( $M=2.45, S D=1.152)$ and America's ( $M=2.63, S D=1.013)$ conditions, $t(51)$, $p=.560$, did not show a significant difference. This finding could validate, irrespective of the geography or economic level of the countries, that the subjects of this study have moderate to no idea about CE. This could be due to the lac 


\begin{tabular}{|c|c|c|c|c|c|}
\hline Location of $\mathrm{HQ}$ & & $\mathrm{N}$ & Mean & Std. Deviation & Std. Error Mean \\
\hline $\begin{array}{l}\text { How important is } \\
\text { circular economy } \\
\text { (CE) concept to }\end{array}$ & Nepal & 29 & 2.45 & 1.152 & 0.214 \\
\hline your organization & USA & 24 & 2.63 & 1.013 & 0.207 \\
\hline
\end{tabular}

Table 3. How important is CE to your organization?

of awareness about CE in the sampled countries involved in this research. Initiation of $\mathrm{CE}$ awareness programs would be an effective intervention to encourage awareness of CE benefits across each country.

Also, respondents of both countries were significantly aware that they have to change their current mode of consumption; on average, $79.2 \%$ of respondents aligned with this statement; whereas, $7.5 \%$ did not agree and $13.2 \%$ were unaware of the issue. All participants identified that the motivation for changing their consumption pattern was to protect resources for the future. Only $14.8 \%$ of the respondents chose financial motives for rationale behind changes in consumption patterns. These findings reconcile with the Liakos et al. (2019) in that CE is still thought of as an environment protection strategy.

\section{Readiness for Sharing an Economic Model}

It is undeniable that the sharing of resources facilitates the circular economy since it is also one of the business models of the CE; Uber and Lyft follow the same business model. $82.8 \%$ of Nepali and $60 \%$ of the USA respondents said they would like to use ride sharing to commute. As ridesharing is relatively new in Nepal, the respondents were excited about it. Similarly, in case of integrating a renting model, Nepal slightly outnumbered the USA respondents in terms of a desire to use such a platform; $72.4 \%$ and $68 \%$ respectively in Nepal and the USA aligned with the renting model. The higher cost of vehicles and household machines in Nepal, in comparison to the USA, might have motivated them to be inclined to use the sharing model. The same was inferred by Liu, Li, Zuo, Zhang, and Wang (2008) in similar research conducted in China.

\section{Enablers of a Circular Economy}

Interestingly, in both countries, the respondents ranked market/consumer awareness as the most important factor for inducing the modality of the $\mathrm{CE}$; specifically, $75.9 \%$ in Nepal and $72 \%$ in the USA. Policy and regulation were chosen as the second enabler for CE in the USA at $60 \%$ and was ranked as the third enabler by the Nepalese respondents at $31 \%$. Corporate social responsibility (CSR) was also selected as a factor that prompted CE related activities; USA respondents averaged at $52 \%$ and Nepalese respondents averaged at $48.3 \%$ for the same. The more collaboration within and outside of an organization, the better the design of the products that support disassembling. The mature end product collection mechanism and investment in R\&D were prioritized higher in the USA than in Nepal.

Though a majority of respondents across the countries were unaware of $C E$, they still thought CE could be an important strategy for sustainability; specifically, $89.3 \%$ in Nepal and $72 \%$ in the USA agreed and strongly agreed for the same clause. This finding aligns with Witjes and Lozano's (2016) conception of how crucial $\mathrm{CE}$ is for sustainability. On the lack of resources forcing companies to adopt a CE modality, 31\% in Nepal and $41.7 \%$ maintain their neutralism, though this was also skewed towards agreeableness in both countries. On statements like profit motive driving companies into $\mathrm{CE}$ and CE being a medium to enter a new market, as aligned with the research findings of Adams, Osmani, Thorpe, and Thornback (2017), the expectation of economic gain was found to motivate companies to incorporate CE. Lastly, on average, $64.7 \%$ of the respondents across the countries remain impartial if CE would assist in getting rid of competitors, $19.6 \%$ agreed and 
strongly agreed; whereas, the remaining respondents refuted the statement.

\section{Organizational Level Arrangement to Support CE}

As per this research, a relatively small percentage of organizations have job positions that are related to managing the CE activities in both countries. In specific, $3.4 \%$ of the respondents in Nepal identified that their organizations had an individual in this role; whereas, $24 \%$ of respondents indicated the same in the USA. Along with the rise in environmentalism, $86 \%$ of the companies listed in Standard and Poor's 500 Index produced a sustainability report in 2018 ("Flash report," 2019). Google, IKEA and Patagonia each have a CE specific report. However, in the case of the researched companies, $96.6 \%$ and $72 \%$ of the respondents from Nepal and the USA respectively selected that their organizations did not publish reports related to their CE activities. $55.2 \%$ respondents from Nepal and $60 \%$ from the USA said their organizations were not concerned about minimalistic utilization of resources at all.

\section{Time to Apply CE Concepts}

The majority of the respondents across the countries identified that there is no time to wait, and companies should work on implementing CE promptly; specifically, $75.9 \%$ in Nepal and $72 \%$ in the USA expressed this thought. Whereas, on average, $31.5 \%$ of respondents, in total, identified that the CE model should have a cost benefit before implementation. Similarly, 10.3\% of respondents in Nepal and $24 \%$ in the USA explained that they would initiate CE activities only if they were demanded by the market. Lastly, $14.8 \%$ and $18.5 \%$, on average, across the sampled countries identified that they would practice CE only if mandated and subsidized by the government respectively.

\section{Conclusion and Recommendations}

Though the respondents in both countries were aware of the importance of environmental conservation, this research found that they had a lack of understanding regarding how CE could be practically implemented at an individual as well as organizational level. The findings from the research could help in bringing policy level interventions to make the public aware of the importance of CE activities.

\section{Discussion}

This comparative study on CE awareness and perception across the USA and Nepal showed that a limited number of respondents have moderate knowledge on $\mathrm{CE}$, and the number of respondents who have expert skills within the field are negligible. Only $48 \%$ of the Americans surveyed and $34.5 \%$ of the Nepalese surveyed expressed that their companies were involved with CE activities. In a similar type of survey conducted in the Netherlands in 2018, only 9\% expressed knowledge of the exact meaning of CE ("Three-quarters of Dutch," 2019). From this, it can be inferred that the concept of CE is muddled. Furthermore, $C E$ is not only related to the $3 R$ approach of waste management, but it unequivocally focuses on the efficient use of resources from the very beginning stage of resource procurement to product design to the final distribution and consumption stage. Yuan, $\mathrm{Bi}$, and Moriguichi (2006) stressed the economic benefit of a CE rather than just the ecological advantages which the respodents of this research were found lacking in knowledge of.

No significant difference in the respondent's perception towards CE across both countries was inferred with the $p$-value of 0.560 at $95 \%$ of the confidence level. The respondents from both countries have little knowledge about the CE activities but have perceived that CE activities were important for their organizations. In comparison to the USA, Nepalese respondents were more positive towards the ridesharing and renting models. This could have been due to the higher cost of vehicles and machines making it unaffordable to buy in Nepal, creating an opportunity for ridesharing companies.

Though contemporarily, in both countries, while the respondents lacked the practical scope of $\mathrm{CE}$, they still deemed awareness of $\mathrm{CE}$ activities as an important factor to induce their organizations to caliber their products to be in line with a CE philosophy. CE was also seen as a 
tool for corporate social responsibility (CSR); Esken, Franco-Garcia, and Fisscher (2018) in their research, supported a complementing relationship between CSR and CE. In comparison to the Nepalese respondents, the USA respondents focused more on organizational structural effectiveness, like interdepartmental relationships and investment in $R \& D$ to promote $\mathrm{CE}$, which in return, has supported symbiosis.

Though a significantly high percentage of respondents in both countries were aware of the need to preserve resources, the organizational level arrangement in researching, designing and developing a CE philosophy were negligible across the sampled countries. Multinational companies like Google and IKEA have started publishing sustainability reports, but almost none of the sampled companies in this research were found to have done so or kept employees responsible for implementing CE philosophies.

Lastly, in both countries, respondents were concerned about resources and their preservation, as $75.9 \%$ of respondents in Nepal and $72 \%$ in the USA indicated desire to apply CE concepts in their organization as soon as possible. This provides an opportunity and affirms higher support from employees when firms transition from a linear to a circular model of operations. However, equal caution should be made as the transition will pay-off only when the benefit outweighs the cost of transition in terms of financial and non-financial resources.

\section{Recommendations}

This research concludes, though the majority of respondents were aware of the need to protect the environment, they lacked a concrete understanding and applicability of CE. A proper understanding of $\mathrm{CE}$ is recommended to create a balance of exchange of resources between a company and its environment. Some of the interventions that are deemed beneficial to promote CE in both countries are listed below and should be considered as recommendations derived from the findings of this small-scale study.

Need to connect the gap between environment awareness and CE philosophy. CE activities are interrelated with environmentalism. CE is the flow and exchange of resources among an organization and the environment. In this research, a significantly higher percentage of respondents were conscious of the need to change their current mode of consumption; whereas, in the meantime, the same sample lacked enough knowledge of $\mathrm{CE}$, as their understandings were limited to the $3 R$ approach. Since there are higher chances of environmentally concerned people supporting the CE philosophy, connecting the gap between these two concepts, i.e. environmentalism and $C E$, is essential to make people aware of the importance of $C E$, which indeed, starts from the ethical use of environmental resources. Effective training, workshops and seminars could alleviate this gap and make people aware of CE.

Making CE a mainstream subject matter. The research concluded that a small percentage of the sampled organizations have CE related activities. Until corporate level management brings a CE philosophy when designing corporate strategies, it will be hard to practice it companywide. Firstly, the management should incorporate CE methodologies like well-designed reverse logistics and modular product designs while formulating the corporate strategies, as it enhances the CE capability of the company. Further, appointing a sustainability or CE officer will make the company more involved with $\mathrm{CE}$ activities. A separate post/position with responsibility in an organizational structure for how/when to implement CE activities will support the implementation of CE and make people more aware of it.

Develop CE awareness programs. Still, significantly lower proportions of organizations know and are aware of CE along with its applicability. Governmental and nongovernmental agencies could help in formulating and implementing the transition from a linear to a circular model of production and consumption. The Ellen Mac Arthur Foundation has been playing a pivotal role in bringing various tools, techniques and methodologies to enact CE. The awareness program could be launched on two levels: i) individual, ii) organizational. 
An increased individual level of awareness is essential to generate change in individuals' consumption habits. This would include making people aware of the disadvantages of using plastics, promoting a habit for reusing consumer goods and letting the public know how they can be active parts of the CE value chain.

At an organizational level, organizing workshops and conferences on CE would encourage employee awareness of its importance. Organizations can begin with auditing existing products and process cycles. These types of interactions and trainings will make organizations more aware of the critical points where CE activities could be introduced, i.e. turning waste into material.

Policy interventions. Rules and regulations can make individuals, as well as organizations, aware of CE activities. It was chosen, by the respondents, as one of the enablers for $\mathrm{CE}$ activities in this research. Policies could be voluntary or mandatory depending upon the readiness of the market to implement. European Union (EU) directives on CE like the EU Action Plan force corporations to abide by $\mathrm{CE}$ procedures. The policies related to subsides, resource utilization, and $3 R$ approaches should be formulated by the government in order to attract and make corporations aware. Lieder and Rashid (2016) inferred the importance of joint support from all stakeholders for the successful implementation of CE on a large scale and a policy in place to support collaboration and cooperation. This policy intervention should promote stakeholder engagement in CE activities and provide them with economic incentives to take the leap from a linear to a circular model.

\section{Further Research}

Though this study has been a useful comparative investigation across two countries, it does have some limitations. The limited number of samples across the country could be increased in the future, and in the same way, a multi-country model could be tested to make the findings more representative. Furthermore, the questionnaire did not fully focus on symbiosis, sharing or servitization which are also integral components of CE and research topics in future. Moreover, the sample contained the majority of respondents from the service industry, and in the future, research could be conducted with a more diverse range of manufacturing firms to determine the level of awareness of the CE. 


\section{REFERENCES}

Adams, K. M., Osmani, M., Thorpe, T., \& Thornback, J. (2017). Circular economy in construction: Current awareness, challenges and enablers. Proceedings of the Institution of Civil Engineers, 170(1), 15-24. doi:10.1680/jwarm.16.00011.

Esken, B., Franco-Garcia, M.-L., \& Fisscher, O. A. (2018). CSR perception as a signpost for circular economy. Management Research Review, 41(5), 586-604. doi:10.1108/MRR-02-2018-0054.

Davis, G., \& Hall, J. A. (2006). Circualr economy legislation: The international experience. World Bank.

Ellen MacArthur Foundation. (2013). Towards the circular economy. Ellen MacArthur Foundation.

Flash Report: $86 \%$ of S\&P 500 Index ${ }^{\circledR}$ companies publish sustainability reports in 2018. (2019, May 16). Retrieved from https://www.3blmedia.com/News/Flash-Report-86-SP-500-Indexr-Companies-Publish-SustainabilityResponsibility-Reports-2018

Govindan, K., \& Hasanagic, M. (2018). A systematic review on drivers, barriers, and practices towards circular economy: A supply chain perspective. International Journal of Production Research, 56(1-2), 278-311. https://doi.org/10.1080/00207543.2017.1402141.

Houten, F. V., \& Ishii, N. (2019, January 24). It's time for the circular economy to go global - and you can help. Retrieved from https://www.weforum.org/agenda/2019/01/its-time-for-the-circular-economy-to-goglobal-and-you-can-help/

Liakos, N., Kumar, V., Pongsakornrungsilp, S., Garza-Reyes, J. A., Gupta, B., \& Pongsakornrungsilp, P. (2019). Understanding circular economy awareness and practices in manufacturing firms. Journal of Enterprise Information Management, 32(4), 563-584. doi:10.1108/JEIM-02-2019-0058.

Lieder, M., \& Rashid, A. (2016). Towards circular economy implementation: A comprehensive review in context of manufacturing industry. Journal of Cleaner Production. 115, 36-51. https://doi.org/10.1016/j.jclepro.2015.12.042.

Liu, Q., Li, H. M., Zuo, X. L., Zhang, F. F., \& Wang, L. (2009). A survey and analysis on public awarness and performance for promoting circular econony in China: A case study from Tianjin. Journal of Cleaner Production, 17(2), 265-270. https://doi.org/10.1016/j.jclepro.2008.06.003.

Ministry of Finance. (2019, May 29). Budget speech of fiscal year 2019/20. Retrieved from https://mof.gov.np/uploads/document/file/budget_speech_website_20190619052055.pdf

Three-quarters of the Dutch people are not familiar with the 'circular economy. (2019, January 17). Retrieved from https://www.duurzaam-ondernemen.nl/driekwart-nederlanders-is-niet-bekend-met-de-circulaireeconomie/

Peters, A. (2019, Feburary 5). Most U.S. companies say they are planning to transition to a circular economy. Retrieved from https://www.fastcompany.com/90300741/most-u-s-companies-say-they-are-planning-totransition-to-a-circular-economy

Upadhayay, S., \& Alqassimi, O. (2018). Transition from linear to circular economy. Westcliff International Journal of Applied Research, 2(2), 62-74. Retrived from https://www.westcliff.edu/wpcontent/uploads/2019/08/Upadhayay-Alqassimi-2018-22.pdf.

World Bank. (2019, August 14). GDP(current US\$). Retrieved from https://data.worldbank.org/indicator/NY.GDP.MKTP.CD?locations=US

World Economic Forum. (2019). A new circular vision for electronic. Time for a global reboot. Geneva: World Economic Forum.

Yuan, Z., Bi, J., \& Moriguichi, Y. (2006). The circular economy: A new development strategy in China. Journal of Industrial Ecology, 10(1-2), 4-8. Retrived from https://search.proquest.com/docview/194919398?accountid=158986. 